\title{
EFFECT OF TITANIUM DIOXIDE NANOPARTICLES ON MECHANI- CAL PROPERTIES OF DENTURE BASE RESIN: AN IN VITRO STUDY
}

\author{
Mamdouh M Mansour," Mohamed Seif Al-Nassr", Ahamed A Shon ${ }^{* * *}$ Mostafa I Fayad ${ }^{* * *}$ and Ramy Abd-Allah ${ }^{* * * *}$
}

\begin{abstract}
Objective: The aim of this study was to illuminate the effect of different concentrations of titanium dioxide nanoparticles on the mechanical properties of heat polymerized acrylic resin. The tested parameters were flexural strength, impact strength, and microhardness.
\end{abstract}

Material and Methods: 60 specimens were prepared according to the specific dimension for each test and allocated to two groups. Group (A) 45 specimens of conventional acrylic resin modified by addition of $1 \%, 3 \%$ and $5 \% \mathrm{TiO}_{2}$ nanoparticles powder. Group (B) 15 specimens of unmodified conventional acrylic resin.

Results: Flexural strength, impact strength, and microhardness were tested for both groups. The data was collected and statistically analyzed. Results: Flexural strength considerably decreased by increasing $\mathrm{TiO}_{2}$ concentration, meanwhile impact strength significantly decreased with increasing $\mathrm{TiO}_{2}$ concentration. The microhardness was significantly increased by increasing $\mathrm{TiO}_{2}$ concentration.

Conclusion: Increasing $\mathrm{TiO}_{2}$ concentration was significantly improving microhardness and diversely affecting flexural strength and impact strength

\section{INTRODUCTION}

Poly-methyl methacrylates is the most commonly used denture base material. Properties that contributed to the success of these materials as a denture base are excellent appearance, ease of processing and ease of repair. However, an inherent disadvantage is the liability of an acrylic resin denture to break during service ${ }^{(1)}$.

Many approaches have been proposed to strengthen the acrylic resin prosthesis including modifying or reinforcing the resin. The most common reinforcing technique is the use of solid metal forms or fibers embedded in the prosthesis ${ }^{(2)}$. Addition of metal fibers was found to improve physical and mechanical properties of acrylic resin, improve its thermal conductivity, curing shrinkage and water sorption ${ }^{(3)}$.

Nanotechnology is the production of material and structures in the range of 0.1 to 100 nanometers by various physical or chemical methods. The smaller dimensions of nanoparticles lead to a high surface area to volume ratio and subsequently change the physical, chemical and biological properties of nanoparticles. The utilization of the nanotechnology will improve restorative material, diagnostic and therapeutic techniques. Nanotechnology has a promising application in dentistry including prosthodontic treatment ${ }^{(4,5)}$.

\footnotetext{
* Demonstrator. Removable Prosthodontic Department, Faculty of Dental Medicine, Boys, Cairo, Al-Azhar University.

** Professor, Removable Prosthodontic Department, Faculty of Dental Medicine, Boys, Cairo, Al-Azhar University.

*** Assistant Professor, Removable Prosthodontic Department, Faculty of Dental Medicine, Al-Azhar University.

**** Lecturer, Dental Biomaterial Department, Faculty of Dental Medicine, Boys, Cairo, Al-Azhar University.
} 
$\mathrm{TiO}_{2}$ nanoparticles are increasingly used owing to the impressive features as nontoxicity, chemically inactive, low cost, high refractive index, antibacterial effect, corrosion resistant and high microhardness. Literature has also showed that nanoscale $\mathrm{TiO}_{2}$ reinforcement agents bring new optical, electrical, physiochemical properties attained at very low $\mathrm{TiO}_{2}$ content, which makes polymer- $\mathrm{TiO}_{2}$ nanocomposites a promising new class of materials. It can be anticipated that it will be commercially beneficial for widespread fields. Moreover, $\mathrm{TiO}_{2}$ nanoparticles have been used as additives to biomaterials in order to induce antimicrobial properties. Antimicrobial activities of $\mathrm{TiO}_{2}$ against Candida albicans, Staphylococcus aureus, Pseudomonas aeruginosa, Escherichia coli, Lactobacillus acidophilus, etc. have been proved by recent studies ${ }^{(6-9)}$.

The present study aimed to investigate the effect of different concentration of titanium dioxide nanoparticles incorporation on flexure strength, hardness and impact strength of conventional acrylic resin denture base material.

\section{MATERIAL AND METHODS}

The heat-cured acrylic resins used in this study were PMMA (Acrosome ${ }^{\mathrm{TM}}$, Egypt) $\mathrm{TiO}_{2}$ nanoparticles with an average diameter less than 20nm (Nanotech ${ }^{\mathrm{TM}}$, Cairo, Egypt).

\section{Sample preparation}

60 specimens were prepared according to the specific dimension for each test and allocated to two groups. Group (A) 45 specimens of conventional acrylic resin modified by addition of $1 \%, 3 \%$ and 5\% $\mathrm{TiO} 2$ nanoparticles powder. Group (B) 15 specimens of unmodified conventional acrylic resin.

The sample dimensions were selected according to specific dimension of each test, $(65 \times 10 \times 2.5 \mathrm{~mm})$ for flexural strength, micro hardness tests and
(50 $\mathrm{mm} \times 6 \mathrm{~mm} \times 4 \mathrm{~mm}$ ) for impact strength test then the wax pattern with specified dimensions was used to form the acrylic samples. Three different concentrations of $\mathrm{TiO}_{2}$ by weight $(1 \%, 3 \%$ and $5 \%)$ were added into heat-cure acrylic resin. The samples were processed with optimal condition according to manufacture instructions (3:1 by volume or $2.5: 1$ by weight) until reaching the dough stage). Conventional packing method and water bath curing for 1.5 hours at $74^{\circ} \mathrm{C}$ were done. After polymerization, the flasks were bench cooled at room temperature for 30 minutes and then placed for 15 minutes under running water before opening. Specimens retrieved were inspected for any irregularity. Faulty specimens were discarded and final specimens were selected for each group. Resin specimens were then stored in water for 2 weeks before testing. Twenty specimens were used for each test [flexural strength, impact strength, and micro hardness] with the total number of 60 of specimens.

\section{Sample grouping.}

Three tests were carried out, each test contains 3 groups. In each group, 20specimens were made (Table 1).

TABLE (1) Groups' classifications.

\begin{tabular}{|c|c|c|c|c|c|}
\hline & \multicolumn{3}{|c|}{$\mathrm{TiO} 2$} & \multirow{2}{*}{ Conventional } & $\begin{array}{c}\text { Total } \\
\text { No }\end{array}$ \\
\cline { 2 - 5 } & $1 \%$ & $3 \%$ & $5 \%$ & 5 & 20 \\
\hline $\begin{array}{c}\text { Flexural } \\
\text { strength }\end{array}$ & 5 & 5 & 5 & 5 & 20 \\
\hline $\begin{array}{c}\text { Micro } \\
\text { hardness }\end{array}$ & 5 & 5 & 5 & 5 & 20 \\
\hline $\begin{array}{c}\text { Impact } \\
\text { strength }\end{array}$ & 5 & 5 & 5 & 5 & 60 \\
\hline & 15 & 15 & 15 & 15 & 6 \\
\hline
\end{tabular}




\section{Flexural strength:}

Specimens were tested by 3-point bend test on Lloyd universal testing machine (Model LRX-plus; Lloyd, UK) the samples were statically compression loaded until fracture at a crosshead speed of 10 $\mathrm{mm} / \mathrm{min}$. The stress-strain curves were recorded with computer software (Nexygen-MT; Lloyd Instruments Ltd). From the stress-strain curve, the flexural strength can be calculated. The calculation of Flexural strength was guided by the formula: $\mathrm{FS}\left(\mathrm{o}^{\prime}\right)=3 \mathrm{~F}(\mathrm{~L}) / 2 \mathrm{wh}^{2}$. Where; $\mathrm{F}$ is the maximum load at the point of fracture, $\mathrm{L}$ is the span length between support, $\mathrm{w}$ is the width of the sample and $\mathrm{h}$ its height.

\section{Impact strength}

After were storing the specimens in distilled water at $37^{\circ} \mathrm{C}$ for 24 hours, a notch was made in the middle of each specimen on one edge with 1.2 $\mathrm{mm}$ lengths using sand paper disk and taper steel file. The specimen was supported horizontally in Charpy's impact testing machine (a pendulum type with a disc shaped hammer) and adjusted to zero line in the machine and the test was performed with $0.5 \mathrm{~J}$. The energy absorbed by the specimen up to fracture was detected and values obtained were tabulated for statistical analysis. The strength required to break the samples was calculated using

The following equation: impact strength =energy absorbed $\div$ (width $\mathrm{x}$ thickness)

\section{Microhardness}

Surface micro-hardness of the specimens was determined using digital display Vickers microhardness tester (Model HVS-50, Lanzhou Huayin Testing Instrument Co., Ltd. China) with a Vickers diamond indenter and a 20X objective lens. A load of $200 \mathrm{~g}$ was applied to the surface of the specimens for 10 seconds. Three indentations were equally placed and not closer than $0.5 \mathrm{~mm}$ to the adjacent indentations, were made on the surface of each specimen. The diagonals lengths of the indentations were measured by built in scaled microscope and Vickers values were converted into micro-hardness values. Micro-hardness was obtained using the following equation: $\mathrm{HV}=1.854 \mathrm{P} / \mathrm{d}^{2}$. Where, $\mathrm{HV}$ is Vickers hardness in $\mathrm{Kgf} / \mathrm{mm}^{2}$, P is the load in $\mathrm{Kgf}$ and $\mathrm{d}$ is the length of the diagonals in $\mathrm{mm}$.

Statistical analysis was done by applying SPSS software package (IBM Company, New York, US) Mean, standard deviation, and minimum and maximum values were calculated for each of the studied groups. One-way ANOVA was used to determine whether significant differences existed between the means of the various studied groups. Tukey test was employed at the chosen level of probability $(\mathrm{p}<0.05)$ to determine if the means were significantly different from each other (Table 2).

TABLE (2). The mean values, standard deviations change percent and $P$ values of some physic mechanical of heat cured acrylic resin and heat cured acrylic resin reinforced with Tio2 nanoparticles.

\begin{tabular}{|c|c|c|c|c|}
\hline TestlMean \pm SD Material & Flexural strength & Vickers microhardness & Impact strength & P value \\
\hline Tio2 1\% & $51.8 \pm 13.2$ & $63.6 \pm 8.2$ & $125.8 \pm 3.0$ & $<0.001 *$ \\
\hline Tio2 3\% & $50.2 \pm 9.4$ & $64.1 \pm 5.1$ & $125.1 \pm 0.5$ & $<0.001 *$ \\
\hline Tio2 5\% & $48.6 \pm 9.2$ & $64.6 \pm 14$. & $124.4 \pm 1.8$ & $<0.001 *$ \\
\hline Control group & $81.2 \pm 4.7$ & $34.4 \pm 5.5$ & $126.7 \pm 1.0$ & $<0.001 *$ \\
\hline
\end{tabular}

p: $p$ value for Post Hoc Test (Tukey) for comparing between control group and each other group.

*: Statistically significant at $p \leq 0.05$. 
Statistical analysis results revealed that significant decrease in flexural strength of heat cured reinforced with Tio2 Nps, non-significant decrease in impact strength of acrylic resin reinforced with Tio2 Nps, significant increase in micro-hardness of heat cured reinforced with Tio2 than conventional heat cured acrylic resin.

\section{DISCUSSION}

Despite the popularity of acrylic resin as denture base material, there are main drawbacks of such material as low fracture resistance, water sorption ${ }^{(11)}$ - Several researchers have been demonstrated that the acrylic resin can show improvement in the physical and mechanical properties such as thermal conductivity polymerization shrinkage, water sorption, fatigue behavior, impact strength and flexural modulus when it is reinforced by metal wire, carbon graphite fibers, ultra-high molecular weight polyethylene, glass fiber, silver or copper. Some of the resin materials from such developments exhibited an excellent balance of impact resistance and flexural properties. However, the processes of etching and impregnation of fibers may be impractical ${ }^{(12-14)}$. In this investigation the authors principally aimed to assess possible changes in the mechanical properties of conventional acrylic resin, in particular, the flexural strength (FS), impact strength and micro-hardness through incorporating of $\mathrm{Tio}_{2}$ nano-particles with three different concentrations $1 \%, 3 \%$ and $5 \%$. The most suitable concentration for the addition of different nano-metals to the acrylic resin that can lead to the best properties is doubtful until now. Moreover, it was found that concentrations above $5 \%$ have led to massive changes occurred in the color of acrylic ${ }^{(15)}$. Therefore, the three concentrations 1\%,3\% and 5\% were selected. Flexural strength of denture base resin is considered the primary mode of clinical failure (16). Based on flexural strength values obtained in the present study, it has been demonstrated that flexural strength would drop by addition of additive to acrylic resin since it acts as impurities ${ }^{(17)}$. This result agrees with the study concluded that the incorporation of $\mathrm{TiO}_{2}$ nano-particles into acrylic resins can adversely affect its flexural strength ${ }^{(18)}$.

Micro-hardness of polymethyl methacrylate reinforced with titanium dioxide nanoparticles in different concentrations demonstrated significant increase more than conventional polymethyl methacrylate. This result agrees with study that concluded that the addition of titanium dioxide nanoparticles to heat cure acrylic resin improve its impact strength, transverse strength and surface hardness ${ }^{(19)}$.Also, the results showed non-significant decrease in the value of impact strength of tested specimens than the control group. This finding is in disagreement with previous investigation which concluded that Adding $1 \% \mathrm{TiO}_{2}$ could enhance the impact strength of the conventional resin material to reach high impact material ${ }^{(18)}$.

\section{CONCLUSIONS}

Within the limitation of the study we could concluded the following:

1. Flexural strength of acrylic resin material reinforced with $\mathrm{TiO}_{2}$ nanoparticles is adversely affected and this effect is directly correlated with concentration of nanoparticles.

2. Improved hardness of the acrylic resin material reinforced with $\mathrm{TiO} 2$ nanoparticles.

3. Non-significant decrease in impact strength of the acrylic resin reinforced with titanium dioxide nano-particles.

\section{REFERENCES}

1. Uzyn G, Herse N, Tinçer T. Effect of five woven fiber reinforcements on the impact and transverse strength of a denture base resin. J Prosth Dent 1999; 81:616-20.

2. Vojdani M, Bagheri R, Khaledi A. Effects of aluminum oxide addition on the flexural strength, surface hardness, and roughness of heat-polymerized acrylic resin. J Dent Sci 2012; 7:238-44. 
3. Rad F, Ghaffar T, Rezaii F, Ramazan A. Effect of nanosilver on thermal and mechanical properties of acrylic base complete denture. J Dent (Tehran) 2014; 11:495-505.

4. Sumaidae RRA. Antifungal action of some natural oils on acrylic resin denture base materials. Al- Rafidain Dent J 2012;12(2):295-300.

5. Ozak S, Ozkan P. Nanotechnology and dentistry. Eur J Dent 2013; 7:145-51.

6. Reijnders, $\mathrm{L}$. The release of $\mathrm{TiO} 2$ and $\mathrm{SiO} 2$ nanoparticles from nanocomposites. Polymer Deg Stab 2009, 94, 873-76.

7. Chatterjee A. Properties improvement of PMMA using nano-TiO2. J App Polymer Sci 2010, 18, 2890-97.

8. Sodagar A, Bahador A, Khalil S, Shahroudi AS, Kassaee MZ. The effect of $\mathrm{TiO} 2$ and $\mathrm{SiO} 2$ nanoparticles on flexural strength of poly(methyl methacrylate) acrylic resins. J Prosthod Res 2013, 57, 15-19.

9. Maneerat C, Hayata Y. Antifungal activity of $\mathrm{TiO} 2$ photocatalysis against penicillium expansum in vitro and in Fruit Tests. Int J Food Microbiol 2006, 107, 99-103.

10. Thamaraiselvi T, Rajeswari S. Biological evaluation of bioceramic materials - a review. Trends Biomater Artif Organs 2004; 18:9-17.

11. UR1 D, R H, A. H. Denture fracture-a survey. Br Dent J. 1994;176(9):342-5

12. Asopaa V, Suresha S, Khandelwala M, Sharmaa V, .Asopab SS, Kairac LS. A comparative evaluation of properties of zir- conia reinforced high impact acrylic resin with that of high impact acrylic resin. Saudi J Dent Res 2015;6(2):146-51.

13. Chen SY, Liang Wm Fau - Yen PS, Yen PS. Reinforcement of acrylic denture base resin by incorporation of various fibers. J Biomed Mater Res. 2001;58(2):203-8.

14. Stipho H. Repair of acrylic resin denture base reinforced with glass fiber. J Prosthet Dent. 1998;80(5):546-50.

15. Shi, J.M., Bao, Y.Z., Huang, Z.M. and Weng, Z.X. Preparation of Poly (Methyl Methacrylate)/Nanometer Calcium Carbonate Composite by in Situ Emulsion Polymerization. J Zhejiang Univ Sci 2004, 5, 709-13.

16. Chitchumnong, P., Brooks, S.C. and Stafford, G.D. Comparison of three- and four-Point flexural strength testing of denture-base polymers. Dent Mat 1989, 5, 2-5.

17. Sodagar, A., Bahador, A., Khalil, S., Shahroudi, A.S. and Kassaee, M.Z. The effect of $\mathrm{TiO} 2$ and $\mathrm{SiO} 2$ nanoparticles on flexural strength of poly(methyl methacrylate) acrylic resins. J Prosthod Res 2013, 57, 15-19.

18. Ashour M, Ahmed ME-S, Yousef M. Althomali, Omar AA. Effect of titanium dioxide nano particles incorporation on mechanical and physical properties on two different types of acrylic resin denture base. World J Nano Scie and Eng 2016;6(3):111-9.

19. Alwan S, Alameer S. Effect of addition of $\mathrm{TiO} 2$ nano particles to heat cure acrylic resin. J Bag Coll Dent. 2016;28(4):86-91. 
